\title{
Condiciones de Vida de la Población Inmigrante del Distrito Central, Honduras, año 2013
}

\author{
${ }^{1}$ LILIAN SIERRA \\ Recibido 10.05.16 / Aprobado 11.08.16
}

\begin{abstract}
RESUMEN. Este artículo se basa en un estudio donde se busca conocer las condiciones de vida de la población inmigrante al Distrito Central ya que la migración interna es un fenómeno que históricamente está asociado con los procesos de desarrollo, las crisis políticas, la industrialización, la urbanización y el mejoramiento en las condiciones de vida de la población. La migración al Distrito Central en los últimos años se ha incrementado. El desplazamiento poblacional ha generado en alguna medida cambios en el espacio geográfico, así como en el modo de vida de los inmigrantes. Las características sociodemográficas más relevantes de los inmigrantes en el Distrito Central son: predomina la procedencia rural mayoritariamente de los municipios de Francisco Morazán y los departamentos de Choluteca y El Paraíso, tienen baja escolaridad, un 52\% está en condiciones de pobreza, tienen bajos ingresos económicos; en su mayoría son parte de la PEA insertadas en actividades de sector informal, los servicios y la industria manufacturera y en el caso de las mujeres estas se encuentran en edad reproductiva que impacta los niveles de fecundidad en el Distrito Central.
\end{abstract}

Palabras Clave: inmigrante, condiciones de vida, Distrito Central, dinámica sociodemográfica.

ABSTRACT. This article is based on a study which seeks to understand the living conditions of the immigrant to the Central District as internal migration is a phenomenon that is historically associated with development processes population, political crises, industrialization, urbanization and improvement in the living conditions of the population. Migration to Central District in recent years has increased. The population shift has generated some extent changes in the geographical space, as well as the way of life of immigrants. The most important socio-demographic characteristics of immigrants are predominantly rural origin mainly in the municipalities of Francisco Morazán and the departments of Choluteca and El Paraíso, have low education, 52\% are in poverty, have low income; mostly they are part of the PEA inserted in informal sector activities, services and manufacturing and in case these are women of reproductive age impacting fertility levels in the Central District.

Keywords: immigrant, living conditions, Central District, socio-demographic dynamic

\section{Introducción}

La movilidad territorial y los desplazamientos geográficos de la población no son un tema nuevo, obedecen a determinadas dinámicas la migración trae consigo grandes cambios en cada uno de los ámbitos, se ha tornado un fenómeno totalmente universal que ha avanzado de manera gradual, a través de los años.

La gran mayoría de los movimientos migratorios de la población latinoamericana, constituyen un complejo proceso social ligado históricamente al desarrollo de sus sociedades, que han expresado y continúan expresando los desequilibrios económicos, sociales y políticos entre países y regiones. En los últimos años el fenómeno migratorio ha dado un giro en la esfera social; en el pasado los que más migraban eran hombres, en la actualidad hay una creciente participación de las mujeres en estos flujos migratorios internos e internacionales.

Honduras al igual que muchos países de la región centroamericana, registra migración interna; que corresponde a poblaciones expulsadas de sus lugares de origen las cuales son atraídas a zonas que han alcanzado mejores condiciones de vida. La migración en el país, está asociada a un sin número de factores: sociales, económicos, culturales, políticos y demográficos. La mayor parte de la población hondureña presenta agudos problemas en materia de pobreza, desigualdad social, desempleo y violencia que se ha agravado, estimulando así la intención de emigrar.

En la última década, el Distrito Central se ha constituido en un punto de concentración y atracción migratoria que

1. Docente de la Carrera de Sociología UNAH, Lic. en Sociología, Máster en Demografía y Desarrollo. sierralilian1@yahoo.com 
ha traído consigo una alta demanda de crecimiento urbano poblacional. Los flujos de inmigrantes han visto en esta ciudad una oportunidad para mejorar sus condiciones de vida. Paralelamente a este crecimiento urbano, es evidente el nivel de abandono en que está sumergida gran parte de estas poblaciones. Es prioritario que las autoridades fijen la mirada hacia los mismos y los perfilen como sujetos del desarrollo, por tanto hay que fortalecer el activo humano de esta población. Este artículo surge a partir de la investigación de tesis en el posgrado en Demografía y Desarrollo y describe las condiciones de vida (demográfica, económica y social) de la población inmigrante hacia el municipio del Distrito Central, departamento de Francisco Morazán.

\section{Metodología}

La investigación se planteó como un estudio mixto (cuantitativo y cualitativo) de corte transversal con un enfoque no experimental y de carácter cuantitativo porque se trabajó bajo una base de datos cuya fuente fue la Encuesta Permanente de Hogares de Propósitos Múltiples (EPHPM) del Instituto Nacional de Estadística de Honduras (INE, para el año 2013).

La unidad de análisis del estudio lo constituyen los 315,903 personas que se identificaron como inmigrantes de la EHPM, se seleccionaron para el estudio algunas variables sociales, económicas y demográficas que determinan las condiciones de vida de los inmigrantes.

Se utilizó el componente cualitativo para hacer visible los motivos de los y las inmigrantes establecidos en el Distrito Central, ya que buscó recuperar la experiencias personales de los inmigrantes que les motivaron seleccionar esta área geográfica como zona de residencia alternativa para mejorar sus condiciones de vida. La técnica que se utilizó fue la entrevista.

\section{Migración interna en Honduras}

La migración interna es un fenómeno sociohistórico que obedece a las demandas de los procesos de industrialización, urbanización y mejoramiento de las condiciones de vida. Es una acción humana que corresponde al traslado original del área rural al área urbana, como producto de las tensiones sociales y económicas que padecen. El propósito del emigrante es encontrar mejores oportunidades en el lugar de atracción, y que el lugar de origen no les facilita. El área urbana resulta ser el mejor atractivo para el emigrante ya que esta concentra servicios educativos, acceso a centros de salud especializados y trabajo, entre otras. Históricamente la migración ha sido un fenómeno de suma importancia para la conformación de las ciudades en Honduras.

La llegada de inmigrantes, más el crecimiento natural de la población, ha dado como resultado un crecimiento acelerado de residentes en las urbes más importantes del país. Con ello ha crecido una mayor demanda de trabajo, alimentos, vivienda, servicios básicos etc., pero además, han surgido situaciones contradictorias como el hacinamiento y la violencia, entre otras. En lo social el crecimiento urbano trae consigo no sólo el incremento poblacional, paralelamente se presenta agotamiento de la institucionalidad y de los servicios del Estado así como del entorno natural.

En las últimas décadas, el fenómeno migratorio se ha convertido en un tema de gran relevancia para los países de América Latina. Uno de los primeros hechos que hizo evidente esta situación, fue la migración del área rural a las ciudades importantes, motivado por la precariedad de sus condiciones de vida ${ }^{2}$, y por los factores de atracción ${ }^{3}$ que estos espacios ofrecían. Un segundo escenario fue la migración internacional, que durante los últimos años se ha incrementado notablemente.

En los años 70's del siglo XX, en los países de América Latina y el Caribe, el tema de la migración fue objeto de numerosas investigaciones nacionales y regionales. En la década de los $80^{\prime} \mathrm{s}$, los flujos migratorios cobraron mayor fuerza a raíz de los conflictos y las guerras civiles que se desarrollaron en la región Centroamericana.

Actualmente con las nuevas dinámicas sociales, culturales y económicas promovidas por la globalización, la migración ha tomado nuevos giros producto de la nueva redistribución de los mercados y del expansionismo geopolítico y económico por parte de los países del primer mundo. Las poblaciones sumidas en la pobreza, han acrecentado los flujos migratorios, situación que sigue siendo un tema de suma importancia y que no puede estar fuera de la agenda de país. Las grandes concentraciones poblacionales, la aguda marginalidad y el agotamiento de los recursos, sugieren que la problemática tiene que ser abordada en materia de políticas públicas y con un enfoque de desarrollo humano sostenible.

2. Condiciones de vida en el contexto de esta investigación son aquellas que propician el desarrollo integral de la persona, es decir que tenga resueltas las necesidades económicas y sociales.

3. Factores de atracción: son imágenes, símbolos, referencias y sobre todo significados expresados en flujos de información que van construyendo una realidad concreta para los migrantes (Rodríguez \& Busso, 2000: 36). 
El inmigrante, como sujeto humano es un ser que tiene necesidades y que genera espectativas que hacen que su propio tiempo y espacio trasciendan en la búsqueda de alternativas.

Los inmigrantes son productos de diversas circunstancias: familiares, laborales, académicas, entre otras. En ellos existe una esperanza, sueños (de un futuro mejor) que provoca la necesidad de migrar. Los inmigrantes son capital humano y social que podría fortalecer la dinámica de vida de las ciudades, pero el hacinamiento urbano y la falta de políticas públicas, ha provocado que a través del tiempo esta población de inmigrantes vivan bajo la sombra de la frustración y la desesperanza.

Los inmigrantes como población diferenciada se ven afectados por la desigualdad social, su momento de precariedad inicial (bajo nivel educativo y de formación) no les permite insertarse en la vida económica y social con calidad, por lo tanto, son víctimas del desempleo, bajos salarios, pocas oportunidades, lo cual contribuye a que se conviertan en población vulnerable y que sobreviven laboralmente del mercado informal.

Según la teoría del Desarrollo Humano, las sociedades deben generar una serie de condiciones que garanticen el pleno desarrollo humano de las personas, como ser mayor esperanza de vida al nacer, acceso a la salud, acceso a la educación, empleos dignos, alimentación adecuada, entre otras, que facilitan la satisfacción de necesidades de las personas. Sin embargo, desde esta perspectiva, la desigualdad violenta la dignidad de la persona humana, porque niega las condiciones de desarrollarse plenamente como persona.

La desigualdad se relaciona con la exclusión social, básicamente las personas que están en mayor situación de desventajas económicas, políticas y sociales respecto a otros grupos, están -en mayor o menor intensidadexcluidos de aquellas oportunidades que ofrece la sociedad. Esto implica que la desigualdad puede tomar múltiples formas y adoptar múltiples consecuencias como ser muerte prematura, mala salud, mala educación, discriminación, pobreza, inseguridad y falta de confianza hacia las personas y hacia uno mismo.

El mejoramiento de las condiciones de vida de la población migrante, está relacionado con las políticas públicas que deberían generarse desde el Estado para disminuir la desigualdad. Para el caso de la migración interna hacia el Distrito Central (Tegucigalpa y Comayagüela), se realiza porque las y los inmigrantes desean salir de la situación de exclusión social y desigualdad que padecen en sus comunidades de origen. Es por ello que este problema de la desigualdad reafirma la situación de quienes son las personas que pueden tener las mejores oportunidades de vida y acceso a los servicios que ofrece el Estado, porque tienen diferencias en sus condiciones de vida sean económicas, políticas o sociales.

La desigualdad social en Honduras ha sido prevalente en la distribución inequitativa de los ingresos, concentración excesiva de la riqueza y el control de los medios de producción, el modelo de desarrollo que se ha implementado ha sido centrado en lo agrícola se ha perdido en las dos últimas décadas capacidad adquisitiva, disminución de los precios de los productos de exportación como ser el banano y el café, industria centrada en las maquilas y la vulnerabilidad climática ante fenómenos naturales como huracanes, sequias producto del cambio climático, mercado regido por la lógica de autorregulación, precarización del empleo, y un Estado débil corrupto, secuestrado por las corporaciones transnacionales, sin recursos, ineficaz y con baja legitimidad en la implementación de políticas de bienestar social. Eso privilegia políticas y programas de asistencia social, en detrimento de un enfoque integral centrado en la salud, la educación, y otros servicios sociales que sirven para reducir inequidades y desigualdades.

El sociólogo Edilberto Torres Rivas (2010) refiere que los regímenes democráticos centroamericanos han profundizado la desigualdad social en la región, ya que defraudan las esperanzas o llenan de incertidumbre a las personas. A este lo llama las "democracias malas" que define como aquellos regímenes democráticos que no satisfacen la confianza de la población (pág. 2). La desconfianza hacia las instituciones del Estado por parte de la población, aunado a la falta de oportunidades en los lugares de origen estimula la inmigración hacia zonas del país donde se observan mejores oportunidades de desarrollo humano y en este caso el Distrito Central y las ciudades de Tegucigalpa y Comayagüela, refleja en las y los inmigrantes esa forma simbólica de desarrollo pleno y satisfacción de necesidades.

Algunos datos afirman esta problemática: para el caso, el informe sobre Desarrollo Humano 2013, identifica a Honduras como el segundo país más pobre de la región centroamericana y según el Instituto Nacional de Estadística la pobreza en el país fue de 64.5\% (INE, 2013). El Distrito Central para el mismo año, contaba con una población de 1,101, 942 habitantes de los cuales el 28.7\% representa la población inmigrante de toda la vida, de esa población el $51 \%$ estaba en condición de pobreza y el $62 \%$ de las inmigrantes eran mujeres. La mayor parte de la población inmigrante vive bajo condiciones de precariedad económica y social, es decir, carecen de un espacio laboral estable, ingresos precarios y tienen bajo nivel educativo. Estas son variables determinantes en las condiciones de vida. 
El impacto de la inmigración en el Distrito Central tuvo su causa en el área rural que fue la más afectada por los modelos de desarrollo lo que provocó incertidumbre y movilizaciones poblacionales. Dicha dinámica demográfica fue generando un impacto en la redistribución espacial de la población, trayendo consigo cambios y transformaciones en la estructura sociodemográfica ${ }^{4}$. El fenómeno latente fue la migración interna que concentró a la población inmigrante en las principales ciudades del país.

\section{Discusión de resultados}

En este capítulo se presentan los principales resultados de la investigación, estos se desglosan en dos partes: las características demográficas y la pobreza

\subsection{Inmigrante por sexo}

El Distrito Central es uno de los municipios de Honduras más atractivos para la migración interna; pues además de ser sede del poder político, concentra servicios de salud, educación y actividades comerciales, las cuales a su vez generan oportunidades laborales. Al revisar los datos de los inmigrantes desagregados por sexo, se puede observar que predomina la población femenina hacia el Distrito Central; el $62 \%$ de los inmigrantes son mujeres y el $38 \%$ hombres. Los datos indican que existe una tendencia hacia la feminización de la inmigración hacia el Distrito Central (Gráfico $\mathrm{N}^{\circ} 1$ ).

Gráfico $\mathrm{N}^{\circ}$ 1. Distrito Central: distribución de inmigrantes por sexo, año 2013

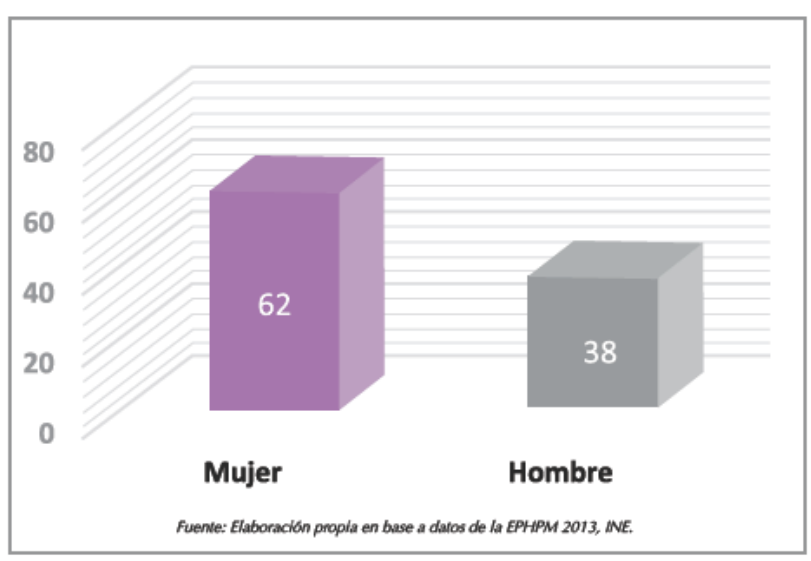

\section{2 Edad de los inmigrantes}

Según la EHPM para el año 2013; Honduras contaba con una población de 8,535,692; de los cuales 4,099,703
(48.0\%) eran hombres y 4,435,988 (52.0\%) son mujeres. La población urbana era de 3,986,354 habitantes, y de ésta el Distrito Central concentra aproximadamente el $27.6 \%$ con $1,101,942$ personas, de los cuales 315,904 era población migrante de toda la vida. Según la estructura poblacional que reflejan la población migrante, ésta en su mayoría es PEA y dentro de ellas mujeres en edad reproductiva.

Al observar la pirámide de población del inmigrante que se traslada al Distrito Central, en su mayoría es población que se concentra en edades entre 15 a 69 años. Por ejemplo del $100 \%$ de los hombres inmigrantes, el $79 \%$ se encontraban entre esas edades. En el caso de las mujeres del $100 \%$ el $81 \%$ también estaban en esas edades de 15 a 64 años.

El grupo de población menor de 15 años apenas representa el 6\%, caso contrario a la población mayor de 64 años que representan el $34 \%$; este porcentaje es relativamente alto es migración de toda la vida (Gráfico $\left.\mathrm{N}^{\circ} 2\right)$.

Gráfico $\mathrm{N}^{\circ} 2$. Distrito Central: pirámide de población inmigrante por edad y sexo, año 2013

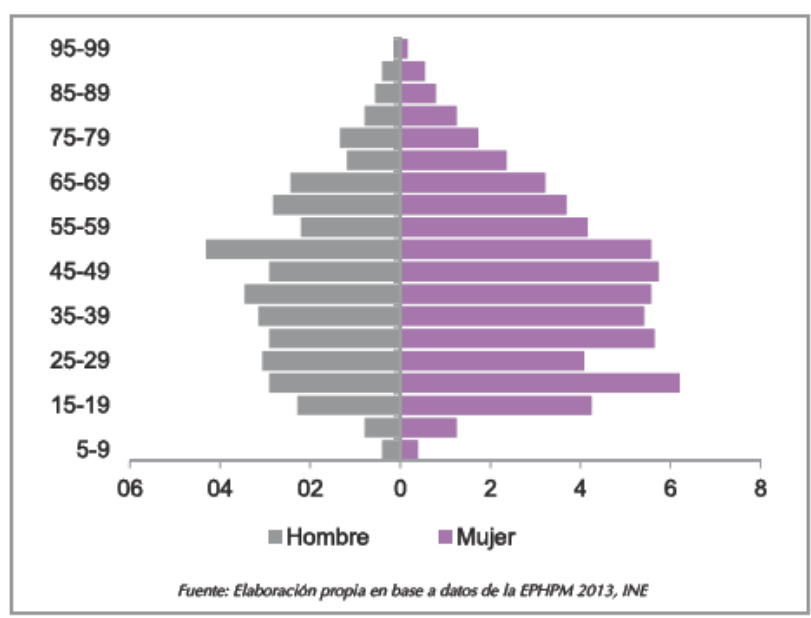

Lo anterior refleja que la distribución por edad en la que se encuentran los hondureños es población joven y mayoritariamente femenina, información que arroja un balance de las demandas a cubrir según los diferentes grupos de edades. Sin embargo, el Estado hondureño responde cada vez menos a las demandas de la población, reduciendo el presupuesto a las carteras de educación, salud, entre otros. Esto además, se verá reflejado en las condiciones de vida de los habitantes que lejos de mejorar en concordancia con el desarrollo humano sostenible, se refleja un deterioro paulatino que disminuye las condiciones de bienestar.

4 Sociodemográfica: caracteristicas poblacionales y sociales que para éste estudio determinan las condiciones de vida de los/as inmigrantes. 
La edad según Welti (1997), es una variable clave para el estudio de una población. La estructura por edades entre la población hondureña ha experimentado cambios y continuará teniendo transformaciones producto de los descensos en las tasas de fecundidad y mortalidad. Esta estructura por edades es heterogénea y con un gran impacto en lo económico y cultural, esto se explica en los cambios en los modos de vida y nuevas visiones del mundo.

\subsection{Procedencia de los inmigrantes}

La mayoría de los inmigrantes que llegan al Distrito Central, provienen de todos los departamentos del país, pero en su mayoría predominan los municipios del departamento de Francisco Morazán que son el 20.3\%. El segundo lugar lo ocupa el departamento de Choluteca con $19.9 \%$ y El Paraíso el tercer lugar con 14\%.

La cercanía y la disponibilidad de vías de comunicación para estos departamentos hacen más fácil el acceso de la migración al Distrito Central. En menor cantidad le siguen los departamentos de Islas de la Bahía $0.1 \%$., Santa Bárbara $1.9 \%$, Lempira $0.5 \%$, Colón $0.6 \%$, Gracias a Dios $0.2 \%$ (Mapa $\mathrm{N}^{\circ} 1$ ).

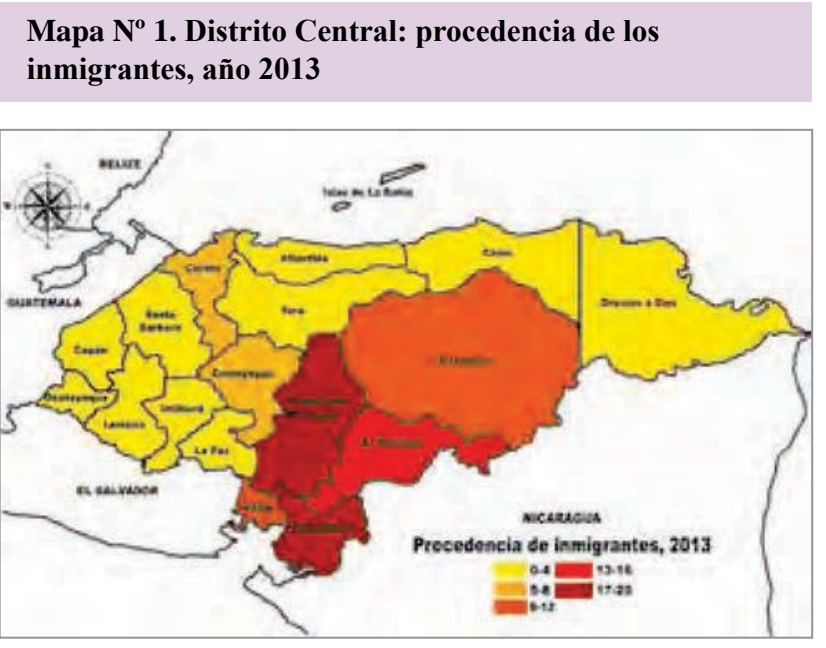

Esta realidad reafirma la teoría planteada por Raventein, que según Rodríguez (2009), las ciudades generan atracción para la población emigrante, dicha motivación consiste en símbolos que se asocian al efecto "imán". Los y las inmigrantes se ven atraídos o deslumbrados por la urbanización que produce: imágenes, símbolos, valores y visiones de la vida. Estas no solo resuelve necesidades objetivas, sino también satisfacen sueños, aspiraciones y expectativas que son requerimientos básicos para la realización personal (Rodríguez, 2009).

\subsection{Nivel de escolaridad de los y las inmigrantes}

Según la UNESCO (2009), la educación es un bien común y un derecho humano del que nadie puede quedar excluido porque gracias a ella es posible desarrollar las capacidades humanas y ejercer los derechos humanos como el acceso a un empleo digno, a la salud, o la participación política (UNESCO, 2009).

La educación como inversión en capital humano, permite a las personas aumentar su espacio de opciones en el mercado laboral y mejorar las condiciones de bienestar ya sea a nivel individual o familiar. El nivel de escolaridad es un factor importante en la búsqueda de un empleo remunerado que logre satisfacer las necesidades de las personas. A menor nivel educativo, menor es la posibilidad de obtener un salario digno y estabilidad laboral; entonces ¿es la educación, un instrumento eficaz que permite a sus pobladores salir de la pobreza y mejorar sus condiciones de vida? Según los testimonios de las/os entrevistados demuestra que la educación es una oportunidad para mejorar las condiciones de vida.

“... En el caso mío yo vine al Distrito Central con las aspiraciones de seguir estudiando, mis condiciones han mejorado porque he tenido otras oportunidades laborales. Ahora soy una catedrática universitaria después de haber sido una maestra de pueblo. Mi peor obstáculo fue ser madre soltera $\mathrm{y}$ tener un niño pequeño y no había quien me lo cuidara”.

(Entrevista 6. Mujer profesional Fecha: 29/09/2015).

“.... Me vine a estudiar y al terminar mis estudios pensaba regresar al pueblo pero aquí me quede. Cuando me vine no era profesional, no tenía casa, condiciones laborales. Pero también el círculo de relaciones sociales se amplió y tuve un cambio de estatus. Me logre graduar y así mejoraron mis condiciones de vida. Me vine con la noción de conseguir una beca y la posibilidad de encontrar trabajo"

(Entrevista caso 7. Hombre profesional. Fecha: 29/09/2015).

Los datos reflejan que existen inmigrantes sin ningún nivel de escolaridad, $4.8 \%$ para los hombres y para las mujeres se registra el $9 \%$, condición que coloca a las mujeres en una posición de vulnerabilidad frente a las oportunidades laborales; ya que las capacidades de las mujeres se reducen al espacio doméstico.

En el caso de la educación secundaria, en promedio alcanza $31 \%$, con ventaja para las mujeres, sin embargo, esta condición cambia cuando se observan los datos del 
nivel de educación superior, pues en este caso los hombres representan el $21 \%$ frente al $17 \%$ que representan las mujeres. El nivel superior para las mujeres no es equitativo con el de los hombres y con esto, se ven expuestas a ser excluidas de las oportunidades de participar en otras funciones sociales y a que no alcancen los niveles óptimos de calidad de vida (Gráfico $\mathrm{N}^{\circ} 3$ ).

Gráfico $\mathrm{N}^{0} 3$. Distrito Central: nivel educativo y sexo de los inmigrantes, año 2013

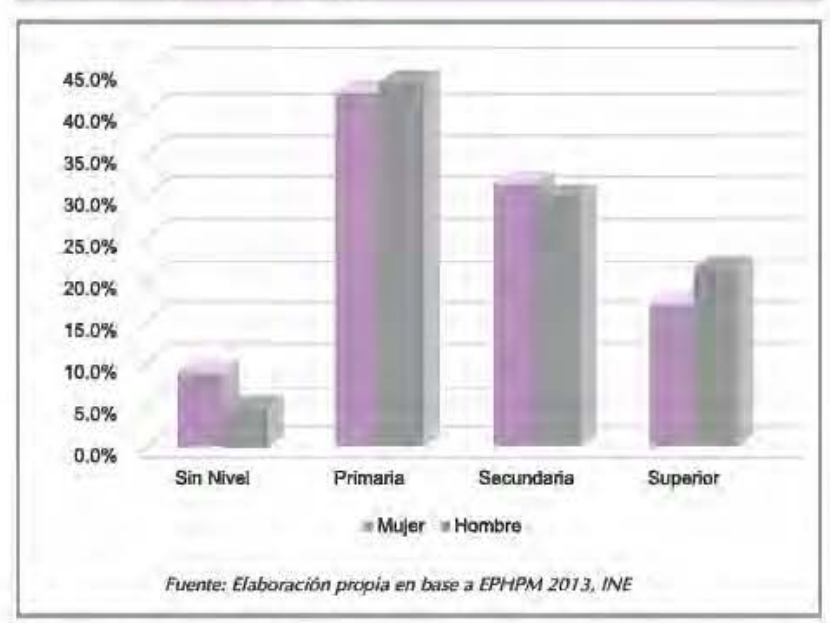

En general el nivel educativo predominante es el de educación primaria, tanto en hombres como en mujeres, sin embargo, en promedio un $19 \%$ de la población inmigrante ha logrado continuar con sus estudios de nivel superior lo que ha favorecido su condición de vida.

Las condiciones de vida precarias en que viven muchos de los habitantes del área rural les impulsan a dejar sus comunidades porque carecen de oportunidades laborales y educativas. Hay factores inductores de la migración y estos son objetivos y se relacionan con la ocurrencia de hechos significativos. En ellos existen diferentes razones que estimulan los movimientos migratorios, como lo son: el ingreso a instituciones de educación superior o la incorporación al mercado de trabajo.
Las demandas educativas producen un impacto económico sobre el sistema educativo a nivel del Distrito Central, conlleva a un incremento de los recursos, tanto materiales como humanos. En el caso de las/ los inmigrantes que llegan al Distrito Central, estos presentan un nivel bajo de escolaridad, predominantemente educación primaria, lo que es congruente con la tendencia a nivel nacional.

Poseer como nivel educativo máximo educación primaria disminuye las oportunidades laborales de los inmigrantes, por lo que su permanecía en el Distrito Central implica enormes retos; pues su nivel escolar limita los espacios laborales e ingresos económicos acordes a una condición de vida digna. La educación es el proceso mediante el cual se facilita el conocimiento y las habilidades motoras, intelectuales y sociales básicas que permiten a las personas tener acceso a nuevos conocimientos y desempeñarse adecuadamente en los campos laborales (CELADE,1988).

\subsection{Nivel educativo de los inmigrantes por edad y sexo}

El acceso a la educación está determinado por razones económicas, sociales y culturales que tienen las personas. A nivel económico se puede decir además que la educación tiene un costo que no siempre es accesible para las familias. La propuesta de educación de calidad para todos en América Latina enfrenta dos desafios importantes en relación con la exclusión. Por lo que está, en primer lugar, ayuda a la superación de la pobreza mejorando masivamente el nivel de formación de las nuevas generaciones que entran al mercado laboral.

En segundo lugar, contribuye a la reducción de las desigualdades sociales, mediante el fortalecimiento de una escuela pública, cuya calidad sea debidamente garantizada por el Estado, para reducir las brechas existentes (UNESCO, 2009). Según los datos estadísticos son los jóvenes los que están apostando por la educación superior en ambos sexos. Los hombres han tenido mayores oportunidades de acceso a este nivel, sin embargo, predomina el nivel educativo de primaria en ambos sexos.

Cuadro $N^{\circ}$ 1. Distrito Central: nivel de educativo de los inmigrantes por edad y sexo, año 2013

\begin{tabular}{|c|c|c|c|c|c|c|c|c|c|c|}
\hline \multirow{3}{*}{$\begin{array}{l}\text { Nivel } \\
\text { educativo }\end{array}$} & \multicolumn{10}{|c|}{ Sexo } \\
\hline & \multicolumn{5}{|c|}{ Mujer } & \multicolumn{5}{|c|}{ Hombre } \\
\hline & 5029 & 30 a 49 & 50 a 65 & $65 y$ mas & Total & $5 \mathrm{a} 29$ & $30 \mathrm{a} 49$ & 50 a 65 & 65 y mas & Total \\
\hline Sin Nivel & $1.9 \%$ & $4.9 \%$ & $11.2 \%$ & $27.5 \%$ & $9.0 \%$ & $1.7 \%$ & $3.8 \%$ & $6.2 \%$ & $9.2 \%$ & $4.8 \%$ \\
\hline Primaria & $3 L 19 \%$ & A5.5\% & $430 \%$ & $51.7 \%$ & $42.2 \%$ & $31,7 \%$ & $41.8 \%$ & $5000 \%$ & $599 \%$ & 15.495 \\
\hline Secundaria & $39.8 \%$ & $31.9 \%$ & $30.7 \%$ & $17.5 \%$ & $31.5 \%$ & $35.0 \%$ & $31.0 \%$ & $29.2 \%$ & $19.7 \%$ & $29.8 \%$ \\
\hline Superior & $27.2 \%$ & $17.2 \%$ & $14.5 \%$ & $2.5 \%$ & $17.0 \%$ & $31.7 \%$ & $22.8 \%$ & $13.8 \%$ & $15.8 \%$ & $21.5 \%$ \\
\hline Total & $100.0 \%$ & $100.0 \%$ & $100.0 \%$ & $100.0 \%$ & $100.0 \%$ & $100.0 \%$ & $100.0 \%$ & $100.0 \%$ & $100.0 \%$ & $100.0 \%$ \\
\hline
\end{tabular}


En Honduras la educación presenta fallas y con estas se crean obstáculos para aquellos que desean mejorar sus condiciones de vida.

La UNESCO, manifiesta que los sistemas educativos, que en el pasado fueron canales de movilidad social y vehículos de integración, se han convertido cada vez más en circuitos segmentados para pobres y ricos, generándose un peligroso circuito de reproducción intergeneracional de la desigualdad (UNESCO, 2009). Las disparidades que se presentan en el sistema educativo son evidentes, la educación privada presenta una oferta educativa con mayores privilegios en relación con la educación pública.

\subsection{Pobreza por sexo de los inmigrantes}

La pobreza es un fenómeno multicausal y multidimensional esta condición ha hecho que se desarrollen diversos métodos de medición de la pobreza. La pobreza es una de las manifestaciones objetivas de la desigualdad social. Asociada a la idea de carencia o privación, de un cierto nivel de ingreso o de consumo así como de capacidades y oportunidades para mejorar la situación personal o familiar. Esta carencia o privación hace que las personas no puedan satisfacer las necesidades económicas y sociales básicas del tipo de sociedad en que viven (Posas, 2006).

En el caso de Honduras la EPHPM del 2013, para conocer las condiciones de pobreza en las que se encuentran los inmigrantes presenta los datos bajo dos tipos de métodos. El método de Línea de Pobreza y el Método de Necesidades Básicas Insatisfechas. El método de Línea de Pobreza, considera tres categorías: pobreza extrema, pobreza relativa y los no pobres. En el Distrito Central para mayo del 2013 , el $64.5 \%$ de los hogares hondureños se encontraban en condiciones de pobreza, ya que sus ingresos están por debajo del costo de la canasta básica de consumo que incluye alimentos, otros bienes y servicios.

En el caso de la población migrante establecida en el Distrito Central, se aprecia que un $51.8 \%$ de la población vive en condiciones de pobreza, de los cuales $20 \%$ se encontraba en pobreza extrema y $31 \%$ en pobreza relativa (Gráfico $\mathrm{N}^{\circ} 4$ ).

La migración no redujo del todo los niveles de pobreza de esta población y con esto el traslado de la pobreza rural a pobreza urbana. Las condiciones de pobreza extrema y relativa de la población inmigrante limitan sus posibilidades de desarrollo y aumentan su precariedad, lo que incide con mayor repunte entre la población en pobreza extrema que es la que tiene las peores condiciones de vida.
Gráfico No 4. Distrito Central: pobreza y sexo de los inmigrantes, año 2013

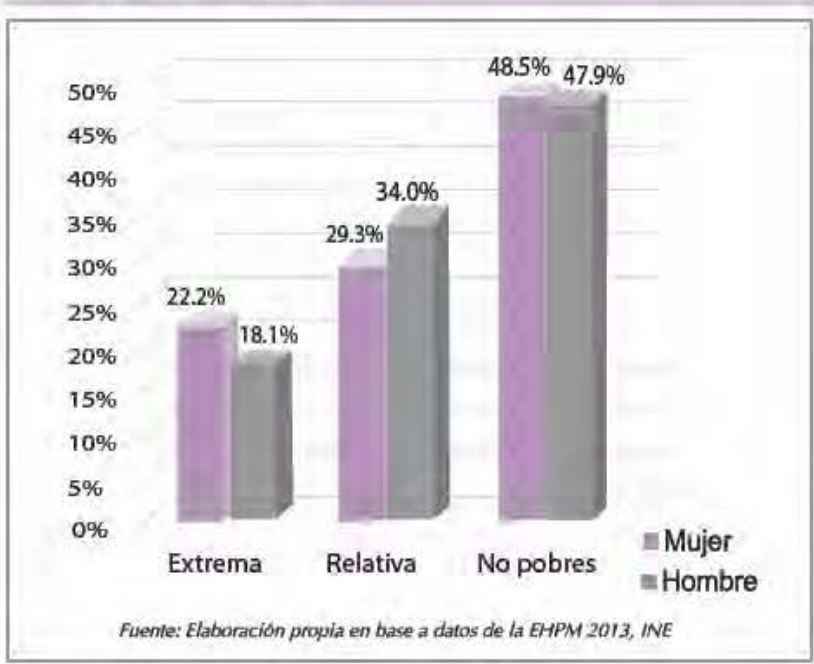

La migración se vuelve una válvula de escape para la población del área rural, las ciudades representan mejores oportunidades de empleo y educación, sin embargo, esta población al salir de sus comunidades tiene bajos niveles educativos y se ven expuesta a incorporarse a un mercado laboral sometidos a explotación de su fuerza de trabajo y bajos salarios.

La teoría de expulsión y atracción expone, que la población emigra a las ciudades porque estas representan mejores condiciones de vida y proporcionan mejores oportunidades económicas. Para que el flujo migratorio se lleve a cabo es porque existen una serie de factores que empujan a abandonar el lugar de origen y que el individuo al comparar las condiciones ventajosas que existen en otros lugares, éstas ejercen una fuerza de atracción, generándose de esta manera, una dinámica de expulsión y atracción (como trabajo, estudios y un mejor ingreso).

La entrevista siguiente refuerza el planteamiento de la teoría antes expuesta.

"En mi pueblo no había nada y por eso me vine a la capital, esta tiene más oportunidades para mi y todos los jóvenes que se vienen buscando mejorar su vida. Yo estudio y trabajo para ayudarle a mi familia que se quedó en el pueblo".

(entrevista caso 11, hombre estudiante universitario. Fecha: 28/09/2015). 


\subsection{Pobreza y nivel de escolaridad}

La educación es un derecho básico de la humanidad, tal como expresa la declaración Universal de los Derechos Humanos en el capítulo veintiséis. La pobreza en que se encuentran muchos de los pobladores se manifiesta como un obstáculo para alcanzar el desarrollo, esta se presenta como la imposibilidad de acceder a los bienes y los recursos básicos (alimentación, vivienda, educación entre otras) para la supervivencia humana y es a través de la educación que las poblaciones logran alcanzar mejores condiciones de vida, ya que se parte de la premisa que a mejor nivel educativo se tienen mejores ingresos salariales.

Los inmigrantes al desplazarse a las zonas urbanas presentan bajos niveles de escolaridad, esto incide en su situación de pobreza. Los inmigrantes sin nivel educativo en pobreza extrema representan el $47.5 \%$, y los inmigrantes que presentan pobreza relativa el $35.5 \%$. Estos datos reflejan que la educación puede ser determinante en la condición de pobreza de los y las inmigrantes, pues es evidente que entre aquellos que no tenían ningún nivel educativo la pobreza les afecto con mayor severidad. En el caso de los inmigrantes no pobres estos poseen mayores niveles de educación superior alcanzando el 90.9\% (Gráfico º 5).

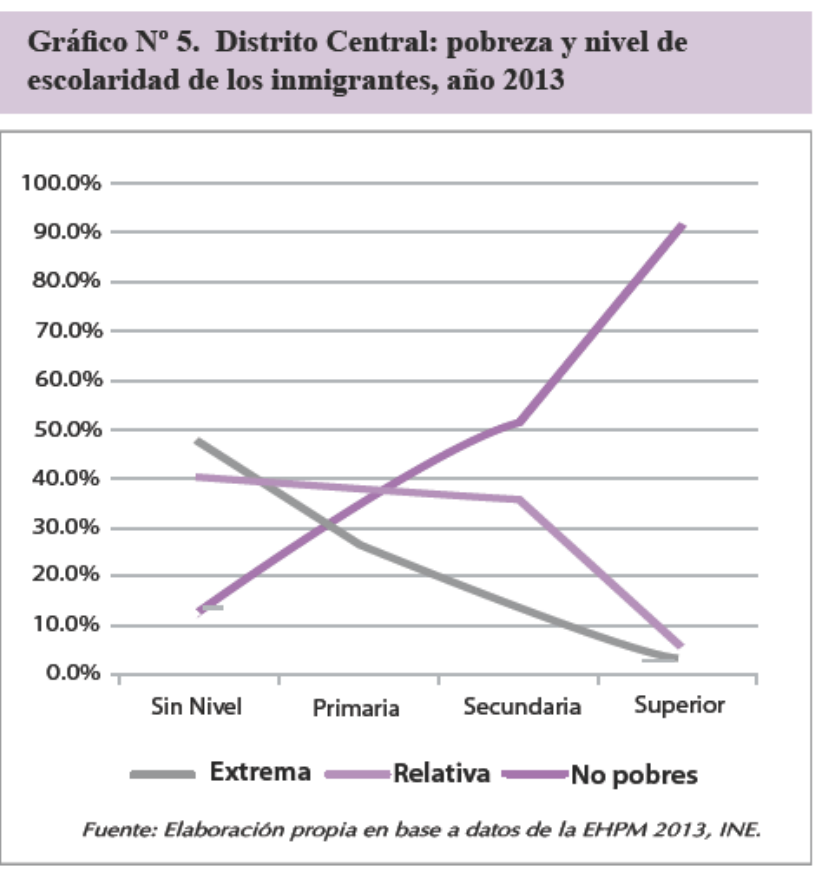

\subsection{Pobreza y salarios de los inmigrantes}

En el territorio nacional el avance en la reducción de la pobreza ha sido lento, pues aun y cuando se han presentado algunos avances relacionados con los Objetivos y Metas del Milenio planteadas hasta 2015, todavía en el tema de pobreza hay mucho por hacer, la pobreza genera exclusión social una buena parte de esta exclusión la sufren los inmigrantes de distintos departamentos que se ubican en el Distrito Central.

La teoría de las disparidades territoriales nos dice que las áreas que presentan mejores condiciones es para muchos pobladores una oportunidad de desarrollo, en la aspiración de cumplir sueños, metas, esperanzas para las personas y mejorar sus condiciones de vida.

Los inmigrantes en situación de pobreza extrema son los que devengan los salarios más precarios: un $2.8 \%$ no devengan ningún tipo de salarios y el $94.4 \%$ devengan menos de un salario mínimo, este nivel de ingresos limita en gran medida la satisfacción de las necesidades familiares las cuales se concentran en alimentación, acceso a agua y energía eléctrica y transporte, el resto de necesidades que presenta el hogar se van postergando. En el caso de los inmigrantes en pobreza relativa $69.1 \%$ devengan menos de un salario mínimo, pero un $28 \%$ devenga entre uno y dos salarios, estos ingresos le permite a ese grupo de inmigrantes acceder a otros tipo de activos como la educación del sistema público, esta inversión a futuro podría permitirles salir de la pobreza. Los no pobres presentan mejores ingresos salariales (Cuadro $\mathrm{N}^{\circ} 2$ ).

Cuadro $\mathrm{N}^{\circ}$ 2. Distrito Central: pobreza y salarios de los inmigrantes, año 2013

\begin{tabular}{|c|c|c|c|c|}
\hline \multicolumn{5}{|c|}{ Pobreza } \\
\hline Salarios & Extrema \% & Relativa $\%$ & No pobres $\%$ & Total \% \\
\hline Cero Salarios & $2.8 \%$ & $0.7 \%$ & $2.1 \%$ & $1.8 \%$ \\
\hline De menos de 1 Salario & $94.4 \%$ & $69.1 \%$ & $36.3 \%$ & $58.0 \%$ \\
\hline De 1-2 Salarios & $2.8 \%$ & $27.9 \%$ & $33.7 \%$ & $26.1 \%$ \\
\hline De 2-3 Salarios & $0.0 \%$ & $2.2 \%$ & $16.8 \%$ & $8.8 \%$ \\
\hline De 3-4 Salarios & $0.0 \%$ & $0.0 \%$ & $3.7 \%$ & $1.8 \%$ \\
\hline De 4 y más Salarios & $0.0 \%$ & $0.0 \%$ & $7.4 \%$ & $3.5 \%$ \\
\hline Total & $100.0 \%$ & $100.0 \%$ & $100.0 \%$ & $100.0 \%$ \\
\hline
\end{tabular}

Fuente: Elaboración propia en base a datos de la EHPM año 2013, INE

4.9 Rama de actividad económica por sexo de los inmigrantes

La población inmigrante que llega al Distrito Central se inserta en el mercado laboral en diversas ocupaciones ${ }^{5}$. En el sector formal e informal de la economía, con diferencias notables por sexo sobre todo porque las ocupaciones masculinas son más diversificadas y mejor remuneradas que las de las mujeres.

5 Las ocupaciones están referidas a cargos y puestos que desempeñan las personas ocupadas. 
La situación de actividad económica, revela que las actividades de mayor representación son los sectores de servicios, comunales, sociales y personales, así como comercio por mayor/menor hoteles/restaurantes e industria manufacturera son los grandes empleadores para los inmigrantes que llegan al Distrito Central en el 2013.

La mujer a pesar de haber mejorado su nivel educativo está más orientada a actividades con mayor representatividad en el comercio y los servicios. Por ejemplo el sector servicios comunales, sociales y personales este sector absorbió el $38.3 \%$ mujeres y el $18.9 \%$ de hombres, seguido por el sector de comercio por mayor/menor hoteles/restaurantes $32.2 \%$ mujeres y $29.8 \%$ los hombres y la industria manufacturera presenta los porcentajes más altos en el que las mujeres están insertas con $18.4 \%$ y hombres con $13.4 \%$.

Analizando las actividades económicas de menor concentración en las mujeres y hombres se identificó que la explotación de minas y canteras representa el $0.3 \%$ en los hombres y $0 \%$ en las mujeres, electricidad, gas y agua los hombres $0.3 \%$ y mujeres $0.7 \%$, agricultura, silvicultura, caza y pesca, hombres $1.4 \%$ y mujeres $0.2 \%$ (Cuadro $\mathrm{N}^{\circ} 3$ ).

Cuadro $\mathrm{N}^{\circ} 3$. Distrito Central: rama de actividad de los inmigrantes según sexo, en porcentaje.

\begin{tabular}{|l|c|c|c|}
\hline \multirow{2}{*}{ Rama de Actividad Económica } & Mujer & $\begin{array}{c}\text { Hombre } \\
\%\end{array}$ & Total \\
\hline Agricultura, Silvicultura, Caza y Pesca & 0.2 & 1.4 & 0.7 \\
\hline Explotación de minas y canteras & 0.0 & 0.3 & 0.1 \\
\hline Industria manufacturera & 18.4 & 13.4 & 16.1 \\
\hline Electricidad, gas y agua & 0.7 & 0.3 & 0.5 \\
\hline Construcción & 0.5 & 16.1 & 7.6 \\
\hline $\begin{array}{l}\text { Comercio por mayor/menor, } \\
\text { Hoteles/Restaurantes }\end{array}$ & 32.2 & 29.8 & 31.1 \\
\hline Transp. almac. y comunic. & 1.6 & 9.3 & 5.1 \\
\hline $\begin{array}{l}\text { Estab. Finac. seguros, bienes } \\
\text { inmuebles y servicios }\end{array}$ & 5.4 & 10.4 & 7.7 \\
\hline Servicios comunales, sociales y personales & 38.3 & 18.9 & 29.5 \\
\hline Busca trabajo por primera vez & 2.7 & 0.2 & 1.6 \\
\hline Total & 100.0 & 100.0 & 100.0 \\
\hline
\end{tabular}

Fuente: Elaboración propia en base a datos de la EHPM año 2013, INE

4.10 Categoría ocupacional y nivel educativo de los inmigrantes

La tendencia de los datos durante el año 2013 muestra que la ocupación de los inmigrantes del Distrito Central en relación a su nivel educativo varía; para el caso entre los que no tienen ningún nivel escolar predomina la categoría ocupacional cuenta propia, con $62.2 \%$, en el caso de los que tienen educación primaria un $45.8 \%$ realiza trabajos por cuenta propia se infiere que se desempeñan en algún tipo de oficios pero también un $35.1 \%$ es empleado del sector privado. Para los que tienen educación secundaria un $38.9 \%$ son cuenta propia, y el mismo porcentaje se inserta como empleado privado. El comportamiento de los datos es distinto para aquellos inmigrantes con niveles de educación superior, de estos $40 \%$ son empleados privado y $36.2 \%$ empleados públicos (Cuadro $\mathrm{N}^{\circ} 4$ ).

El Neoliberalismo instalado en el territorio nacional surge con la iniciativa de la explotación del capital humano local y tiene la característica de abaratar el costo de la mano de obra con largas y extendidas horas de trabajo, así mismo deteriora el salario real de los trabajadores y trabajadoras, produciendo perdidas de beneficios sociales reconocidos por las leyes.

Cuadro No 4. Distrito Central: categoría ocupacional y nivel educativo de los inmigrantes, año 2013

\begin{tabular}{|l|c|c|c|c|}
\hline \multicolumn{5}{|c|}{ Nivel de Escolaridad } \\
\hline $\begin{array}{l}\text { Categoría } \\
\text { Ocupacional }\end{array}$ & Sin Nivel & Primaria & Secundaria & Superior \\
\hline Empleado Público & $2.7 \%$ & $4.7 \%$ & $13.2 \%$ & $36.2 \%$ \\
\hline Empleado Privado & $18.9 \%$ & $35.1 \%$ & $38.9 \%$ & $40.0 \%$ \\
\hline Empleada Doméstica & $16.2 \%$ & $11.6 \%$ & $2.6 \%$ & $0.0 \%$ \\
\hline Cuenta Propia & $62.2 \%$ & $45.8 \%$ & $38.9 \%$ & $21.5 \%$ \\
\hline $\begin{array}{l}\text { Trabajador no } \\
\text { Remunerado }\end{array}$ & $0.0 \%$ & $2.8 \%$ & $6.4 \%$ & $2.3 \%$ \\
\hline Total & $100.0 \%$ & $100.0 \%$ & $100.0 \%$ & $100.0 \%$ \\
\hline
\end{tabular}

Fuente: Elaboración propia en base a datos de la EHPM año 2013, LNE

\subsection{Nivel de empleo y sexo de los inmigrantes}

Uno de los problemas que enfrenta la población inmigrante que se traslada al Distrito Central, es la precariedad de los mercados laborales en la ciudad, que generalmente implica la inserción de una buena parte de la población en subempleo visible e invisible. La falta de empleo constituye el principal factor por el que los inmigrantes dejan su lugar de origen. Cada año muchos jóvenes se preparan y culminan sus estudios de educación secundaria con la esperanza de poder obtener un empleo que les permita subsistir, pero al salir se encuentran con escasas oportunidades; en un ambiente donde hay mucha demanda y pocas ofertas y en algunos casos la inseguridad.

Gran parte de los/las inmigrantes se encuentran sin trabajo en el sector formal de la economía en el Distrito 
Central razón por la cual deben realizar cualquier actividad laboral para poder sobrevivir, aunque estos no sean trabajos de tiempo completo. Lo anterior da como resultado que la población inmigrante, en su deseo de incorporarse al mercado de trabajo ofrece su mano de obra barata, operando en condiciones de precariedad.

"El trabajo que tengo no es lo que deseo para toda mi vida, de cierta manera no he logrado mejorar mis condiciones de vida y solo he logrado cubrir lo básico, ya que el dinero no me alcanza por el salario que tengo"

Entrevista caso 13, hombre universitario. Fecha: 25/09/2015).

Según los datos, el $41.8 \%$ de los hombres y el $41.2 \%$ de las mujeres no tienen problemas de empleo; sin embargo, el $11.2 \%$ de las mujeres y el $11.0 \%$ de los hombres tienen inestabilidad laboral y salarial que corresponde a los sub empleados visibles ${ }^{6}$ que trabajan más de 36 horas a la semana y que con deseos de seguir trabajando no logran estabilidad laboral. El $46.9 \%$ hombres y $47.7 \%$ mujeres estaban en condiciones de subempleo invisible ${ }^{7}$, tuvieron ingresos mensuales inferiores al salario mínimo promedio mensual, cuyas condiciones son más precarias porque aunque trabajen más de 36 horas a la semana sus ingresos no equivalen a un salario mensual y estos no cubren sus necesidades básicas para mejorar sus condiciones de vida (Cuadro $\mathrm{N}^{\circ} 4$ ).

\section{Gráfico $N^{\circ}$ 6. Distrito Central: nivel de empleo de los inmigrantes por sexo, año 2013}

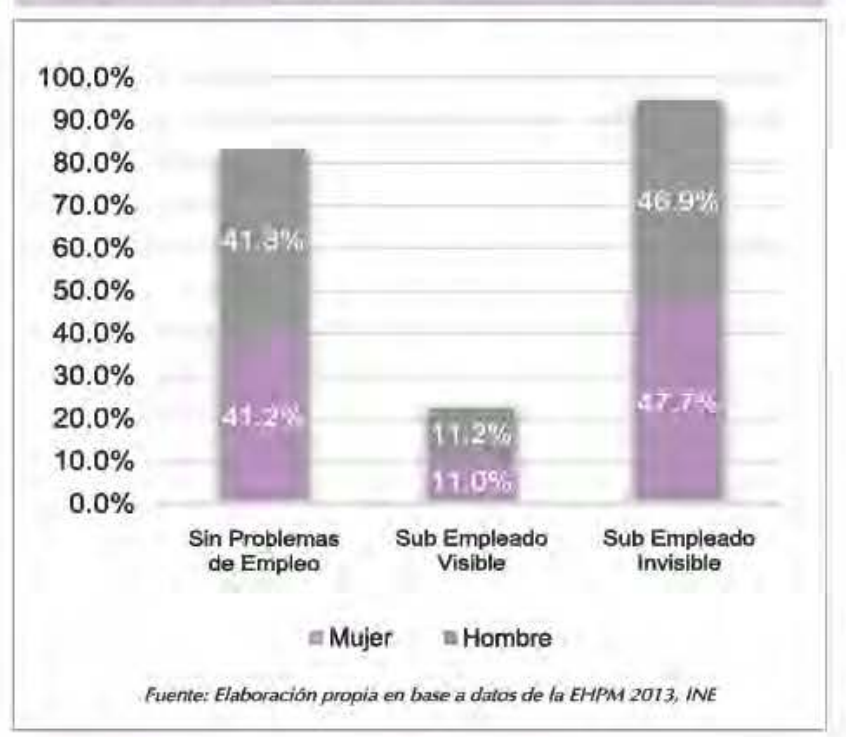

4.12 Ingreso salarial por ocupación principal de los inmigrantes según sexo

El nivel educativo tiene consecuencias significativas para los inmigrantes al momento de insertarse en el mercado laboral, pues algunos trabajos requieren de calificaciones que la mayoría de los migrantes no tiene, en ese sentido, los espacios laborales se reducen.

El costo de la canasta básica que necesita un hogar hondureño sobrepasa la capacidad adquisitiva del que gana un salario mínimo (Lps.7,419) INE 2013. Con este ingreso no se puede garantizar calidad de vida.

Los datos reflejan que los inmigrantes que logran insertarse al mercado laboral en el Distrito Central tienen en su mayoría ingresos salariales inferiores al salario mínimo. En general las mujeres perciben menores ingresos que los hombres. Estos datos reflejan que las condiciones salariales de los/las inmigrantes son precarias (Gráfico $\mathrm{N}^{\circ} 7$ ).

Gráfico $N^{\circ}$ 7. Dístrito Central: ingreso salarial por ocupación principal de los inmigrantes según sexo, ลกิ์ 2013

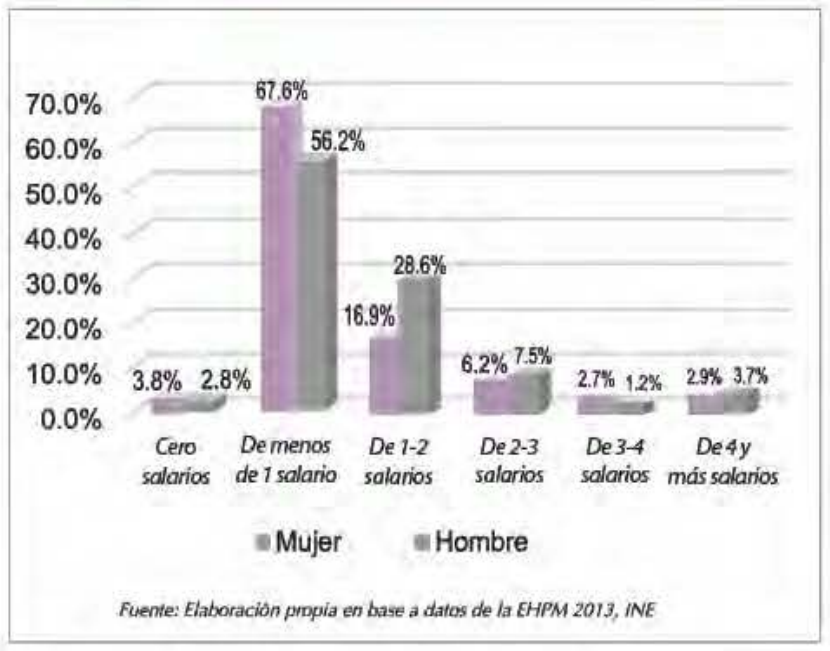

Los ingresos determinan en alguna medida la calidad de vida de la población, sobre todo al momento de cubrir las necesidades básicas del hogar y de cada uno de sus miembros.

En la entrevista siguiente se evidencia que el estudio influye en el ingreso que perciben los inmigrantes para cubrir sus necesidades básicas. 
"Cuando yo me vine... fue para trabajar, pero algunas veces trabajo. Siento que mis condiciones de vida han mejorado más o menos ya que por una parte ya no alquilo $\mathrm{y}$ ahora tenemos una casita, pero por la otra no, porque no tengo un salario estable. Mi mayor obstáculo... el estudio que tengo no me ayuda... es muy bajo, tengo nivel primario".

(Entrevista casol5, hombre asistente de jardinería. Fecha: 13/10/2015).

\subsection{Ingreso salarial por ocupación principal, nivel} educativo y sexo

La EPHPM año 2013, pone de manifiesto la realidad de los inmigrantes de toda la vida del Distrito Central en el plano educativo y salarial, en donde se hace visible cuantitativamente, que en la medida que alcanzan niveles de escolaridad, los salarios van aumentando y mejorando.

Hay que destacar en primer lugar que el ingreso y la ocupación laboral se encuentran asociadas a niveles educativos superiores o bajos.

En el caso de las mujeres inmigrantes que devengaban menos de un salario, un $96 \%$ no tenía ningún nivel educativo, $89 \%$ solo tenía educación primaria, $60 \%$ educación secundaria y $20 \%$ educación superior. El caso de los hombres inmigrantes que devengaban menos de un salario mínimo $100 \%$ no tenía ningún nivel escolar, $72 \%$ tenía educación primaria, $48 \%$ educación secundaria y $21 \%$ educación superior. En otras palabras a medida aumenta el nivel escolar disminuye la cantidad de mujeres y hombres que devengaban menos de un salario mínimo (Cuadro $\mathrm{N}^{\circ} 5$ ).

\section{Conclusiones}

- Las mujeres y los hombres como inmigrantes expresan características diversas tanto en los aspectos demográficos, económicos y sociales. Las condiciones de vida manifiestan cierta dualidad que indica un bienestar o una precariedad. El impacto de la migración interna hacia el Distrito Central puede medirse con variables demográficas, económicas y sociales determinando la demanda de servicios y necesidades básicas de las personas migrantes lo cual puede convertirse en un dato importante para la elaboración de políticas públicas a largo plazo.

Las características sociodemográficas más relevantes que refleja la investigación destacan que la desigualdad predomina mayoritariamente en la población de mujeres inmigrantes, con baja escolaridad y en condiciones de pobreza, y en su mayoría PEA y dentro de ellas mujeres en edad reproductiva lo que de alguna manera impacta los niveles de fecundidad en el Distrito Central.

- Los inmigrantes en su mayoría poseen educación primaria esto de alguna manera ha limitado sus oportunidades de empleo, la mayoría se ubica en el sector del comercio especialmente comercio informal, en los servicios y en la industria manufacturera. Los niveles de escolaridad el acceso a espacio laborales e ingresos denotan ciertos grados de calidad. Por ejemplo la educación que es un activo humano, es uno de los ejes más débiles que afecta tanto a hombres como a mujeres inmigrantes. Se concluye que la mayoría de datos analizados de la migración hacia el Distrito Central, las personas tienen baja escolaridad (nivel primario) y esto tiene un alto significado de vulnerabilidad para este grupo social, por la falta de oportunidades que genera esta condición social.

Cuadro $N^{0} 5$. Distrito Central: ingreso salarial por ocupación principal, sexo y nivel educativo, años 2013

\begin{tabular}{|c|c|c|c|c|c|c|c|c|c|c|}
\hline \multirow{3}{*}{ Salarios } & \multicolumn{10}{|c|}{ Sexo } \\
\hline & \multicolumn{5}{|c|}{ Mujer / Nivel Educativo } & \multicolumn{5}{|c|}{ Hombre / Nivel Educativo } \\
\hline & $\begin{array}{c}\text { Sin } \\
\text { Nivel }\end{array}$ & Primaria & Secundaria & Superior & Total & $\begin{array}{c}\text { Sin } \\
\text { Nivel }\end{array}$ & Primaria & Secundaria & Superior & Total \\
\hline Cero salarios & $0 \%$ & $3 \%$ & $5 \%$ & $6 \%$ & $4 \%$ & $0 \%$ & $1 \%$ & $2 \%$ & $9 \%$ & $3 \%$ \\
\hline Menos de 1 salario & $96 \%$ & $89 \%$ & $60 \%$ & $20 \%$ & $68 \%$ & $100 \%$ & $72 \%$ & $48 \%$ & $21 \%$ & $56 \%$ \\
\hline De 1-2 salarios & $4 \%$ & $8 \%$ & $24 \%$ & $30 \%$ & $17 \%$ & $0 \%$ & $25 \%$ & $38 \%$ & $28 \%$ & $29 \%$ \\
\hline De 2-3 salarios & $0 \%$ & $0 \%$ & $8 \%$ & $19 \%$ & $6 \%$ & $0 \%$ & $2 \%$ & $9 \%$ & $21 \%$ & $7 \%$ \\
\hline De 3-4 salarios & $0 \%$ & $0 \%$ & $2 \%$ & $12 \%$ & $3 \%$ & $0 \%$ & $0 \%$ & $1 \%$ & $5 \%$ & $1 \%$ \\
\hline De 4 y más salarios & $0 \%$ & $1 \%$ & $1 \%$ & $13 \%$ & $3 \%$ & $0 \%$ & $1 \%$ & $1 \%$ & $17 \%$ & $4 \%$ \\
\hline Total & $100 \%$ & $100 \%$ & $100 \%$ & $100 \%$ & $100 \%$ & $100 \%$ & $100 \%$ & $100 \%$ & $100 \%$ & $100 \%$ \\
\hline
\end{tabular}

Fuente: Elaboración propia en base a datos de la EHPM aflo 2013, LNE 
La ciudad como escenario complejo y diferenciado por su división social del trabajo exige especializaciones enmarcadas en el sistema educativo nacional, que para los inmigrantes constituye un reto que se entrecruza entre sus aspiraciones y capacidades humanas. Las condiciones de vida que tienen los migrantes que se encuentran en condición de pobreza $(52 \%)$ chocan con la realidad de un entorno de ciudad, mejorar sus condiciones de vida esta situación se convierte en un proyecto a largo plazo.

- Según los hallazgos de este estudio, la mayoría de los inmigrantes hacia el Distrito Central se vinieron por motivos laborales. El acceso a un trabajo digno no ha sido fácil ya que esto tiene un valor agregado que es la educación y sin desagregar la importancia que tienen los círculos sociales. No tener un trabajo es un punto de inflexión que quiebra todo tipo de aspiración o esperanza. Este fenómeno provoca que la PEA inmigrante, pase a ser parte de la población desempleada o en condiciones de subempleo invisible y visible, esto incrementa el sector informal de la economía dentro de la ciudad del Distrito Central.

- Todo individuo tiene derecho a la libre locomoción, el Artículo 81 de la Constitución de la República de Honduras garantiza esta condición, por lo tanto tiene derecho a emigrar al lugar que el desee sin importar los motivos por los cuales se traslada de un lugar a otro. Sin embargo llama la atención el hecho de que muchos inmigrantes se establecieron en el Distrito Central por motivos de trabajo. Esto responde a la lógica de la pobreza y de desigualdad social que existe en el país, pues muchas comunidades del interior del país tienen limitadas condiciones de vida, convirtiéndose en territorios dispares y sin atractivos para establecerse o permanecer en ellas.

\section{Bibliografía}

- CELADE (1988). Censo de Reducciones Indigenas Seleccionadas: Analisis Sociodemográfico. Santiago de Chile: CELADE.

- CEPAL. (2013) Panorama Social de América Latina. Publicacion Naciones Unidas. Chile. Recuperado de http://repositorio.cepal.org/bitstream/ handle/11362/35917/S20131079_es.pdf?sequence $=1$.

- Jorge Rodríguez, G. B (2009). Migración interna y dsarrollo en América Latina entre 1980-2005. Un estudio comparativo con perspectiva regional basado en siete países. Santiago de Chile: CEPAL.

- INE (2013) Encuesta Permanente de Hogares de propositos Multiples. Tegucigalpa, Honduras.

- Población y Desarrollo: Argonautas y Caminantes (2007). Tegucigalpa.

- Posas, Mario (2006). Sociología General. Tegucigalpa, Honduras.

- Torres-Rivas, Edelberto (2010). "Las democracias malas en Centroamérica. Para entender lo de Honduras, una introducción a Centroamérica” en Cuadernos del Pensamiento Crítico Latinoamericano $\mathrm{N}^{\circ} 33$. CLACSO, agosto de 2010. Publicado en La Jornada de México, Página 12 de Argentina y Le Monde Diplomatique de Bolivia, Brasil, Colombia, Chile, España y Perú.

- UNESCO (2009). Experiencias Educativas de Segunda Oportunidad.Lecciones desde la práctica innovadora en América Latina. Santiago de Chile : UNESCO.

- Welti, Carlos, Herrera A, Macias H \& Trigo Ramón. (1997). Demografia I. Santiago de Chile: PROLAP IISUNAM. 